\title{
STUDIES ON ENGINEERING PROPERTIES OF BINDERS LOADED WITH NANO-FILLERS FOR BETTER DESIGNED COMPOSITES
}

\author{
Rajesh Katiyar ${ }^{1}$, Rajesh Kumar ${ }^{2}$ \\ ${ }^{1}$ Associate Professor, Department of Chemical Engineering, \\ Harcourt Butler Technological University, Kanpur-208002, India \\ ${ }^{2}$ M.Tech. Scholar, Department of Chemical Engineering, \\ Harcourt Butler Technological University, Kanpur-208002, India
}

\begin{abstract}
The study of single lap adhesive joints has been done to find out the mechanical strengths of variable overlap length, establishing maximum load bearing capacity using two component epoxy resin as binding material. The engineering properties studied are joint tensile strength and adhesive shear strength. The dimensions of the adherend metal plates were $25.4 \mathrm{~mm} \times 102 \mathrm{~mm} \times 1.63 \mathrm{~mm}$ $(w \times l \times h)$ with the variation done in overlap length. Aluminium as the adherend and epoxy resin loaded with the nano size $\mathrm{Al}_{2} \mathrm{O}_{3}$ and fumed silica powder as fillers have been used for the preparation of joint specimen. Pre-bond surface treatment of the aluminium substrate was performed in accordance with the procedure as provided by IS 13199:1991. Guidelines for bonded joint preparation and test as per ASTM D1002-99 has been followed. The mechanical properties of the geometrically bonded specimen have been determined under tension loading by Instron1195 UTM at room temperature with testing speed as per standards. The study is focussed on the effect of the overlap length and additives on the joint tensile strength. Adhesive characteristics as well as adherend properties influence the limit strength of the joint that would be obtained. The results are useful in the design of the composites when looking for the specific joint strengths.
\end{abstract}

Keywords: Single Lap Joint, Epoxy Resin, Engineering Properties, Fillers, Aluminium Substrate, Instron1195 UTM.

\section{INTRODUCTION}

In recent times research activities have been largely focused on incorporating binders with filler because polymer based filler composite exhibit much better mechanical, thermal and multifunctional properties when compared with polymer matrices. Nano and micro particle incorporation into the binder is an economical and eco-friendly way to modify the physical and chemical properties of polymer. Nano particles possess increased chemical activity and physical properties. Nano particles type as well as the surface roughness of the faces to be bonded also have some influence on the strength of the adhesive or the binder [1,7]. The joining of thin sections of metals with adhesive binders of improved properties are having better stress distribution and ability to handle dissimilar materials at lower fabrication costs. These joints also have advantages of excellent thermal and insulation properties, superior damping, noise reduction and better corrosion resistance. To improve various properties of structural binders, the metallic or non-metallic powders as filler have been widely used. The addition of fillers reduces the shrinkage while curing, as well as enhances strength and toughness of adhesive binders. A variation in type, amount and size of powders influences the mechanical properties of the reinforced binders [2].

The adhesive bonded joints are most widely used in load bearing structures and of great interest in engineering aspects in the aerospace, automotive industry and in other process sectors as well. Here structures built from several components are joined by means of adhesives to reduce stress concentrations, weight and make manufacturing easy in comparison to traditional joining methods. The adhesive binder serves as a medium for load transmission in adhesive bonding. The load is transmitted from one adherend to another adherend smoothly through the adhesive layer in the overlap region. Single lap joints being the most widely used adhesive joints are the subject of considerable research [3, 8]. Geometrical configuration of bonded parts is essential to obtain enough structural strength, load bearing capacity and long term performance of the joints. As the binder serves as a medium for load transmission, the adhering conditions are also important to attain the joint strength. These conditions are the surface roughness of adhering surface, the thickness of the adhesive layer, the required pressure applied to adhesive resin and its holding time. Also the required curing conditions of adhesive resin are the substantial factor affecting the joint strength. Since binder strength is affected by the many physical and chemical factors, knowing the stress-strain distribution through the adhesive joint becomes important for the integrity assessment of the engineering component [4].

The single lap joint is the most studied type of joint for application in structural components. It involves factors which need to be quantified like overlap length, yielding of the adherend, plasticity of the adhesive and the bond line thickness. Though the adherend is supposed to remain in the elastic range, the substrate may yield in certain cases like aluminium or low strength steel. If the adhesive is very ductile and the adherends are elastic, the joint strength is 
given by the load corresponding to the total plastic deformation. Also the adhesive thickness has an important effect on the joint strength [5]. Fillers have important role in polymer composites due to their ability to effectively transfer the applied load in the matrix. Effective utilization of the nano fillers in structural composites depends on their homogenous dispersion in the matrix. Along with other factors the adhesion of a polymer to the surface of filler particles influence substantially the structure and properties of polymer composites reinforced with fillers [6, 9]. In the present work study of effect of fillers (fumed silica and nano alumina) as additives was done on the mechanical strength of the aluminium joints using epoxy resin as binding material. Aluminium was used as adherend and metal specimen were bonded under single lap joint as per ASTM D1002-99 and tested for mechanical properties by tension loading [10]. Tension test determines how the specific material would react or respond to forces when applied in tension.

\section{MATERIALS AND METHODS}

\subsection{Materials Used}

The epoxy resins of the grade AV 138M from Huntsman Advanced Materials (Hong Kong) Ltd was utilized along with the Hardener HV 998 as the curing agent. This epoxy grade is a two component, room temperature curing paste adhesive of high strength and toughness. Fillers used are Alumina nano powder $\left(\mathrm{Al}_{2} \mathrm{O}_{3}\right)$ with average particle size of 20-30 nm and fumed silica with primary particle size of around $7 \mathrm{~nm}$. Fumed silica is synthesized by high temperature hydrolysis of $\mathrm{SiCl}_{4}$ in $\mathrm{O}_{2}\left(\mathrm{~N}_{2}\right) / \mathrm{H}_{2}$ flame. It is amorphous in nature and possesses very high specific area. Alumina powder was procured from Sisco Research Laboratories Pvt. Ltd., India and fumed silica from SigmaAldrich. The metal sheet (Aluminium) was used in standard available thickness of $1.63 \mathrm{~mm}$.

\subsection{Joint Geometry}

The single lap joint geometry has been shown in figure 1 . Thickness, $\boldsymbol{h}$ of the adherend used was $1.63 \mathrm{~mm}$. Overlap, $\boldsymbol{m}$ as shown has been varied. Width and length of the adherend specimen has been shown by $\boldsymbol{w}$ and $\boldsymbol{l}$ respectively. Adhesive thickness, $\boldsymbol{g}$ has been controlled as per procedure suggested by resin manufacturer. ASTM D1002-99 standard covers the most widely used adhesive bond test for the single overlap joint and suggests the procedure for the determination of apparent shear strengths of adhesives for bonding metals under this geometry.

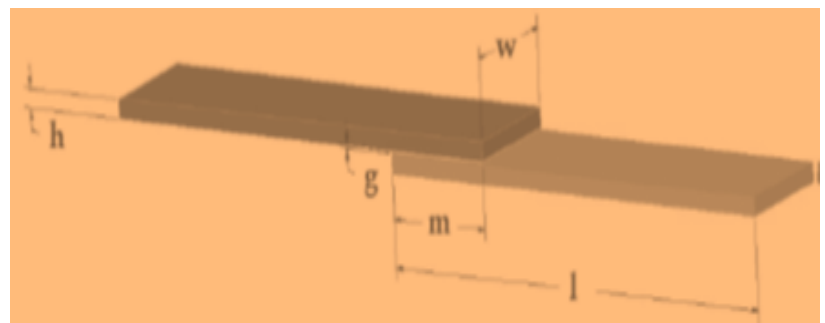

Fig -1: Single lap joint

\subsection{Surface Preparation}

Surface preparation is very important aspect, because bonding performance is quite dependent on the surface quality. High strength bonds can be obtained with appropriate surface preparation as the prepared surface increase contact area between the adherends and binders. Pre-bond surface treatment for the aluminium substrate was carried in accordance with the guidelines as provided by IS 13199:1991. The strength and durability of a bonded joint are dependent on proper treatment of the surfaces to be bonded. Surface treatment was done sequentially starting by solvent cleaning, intermediate cleaning followed by mechanical abrasion. For the enhancement of contact area, silicon carbide paper of 80 grits (80\#) was used in the abrading process. Figure 2 is showing the prepared surface of the aluminium metal adherends in dimensions as mentioned earlier in joint geometry.

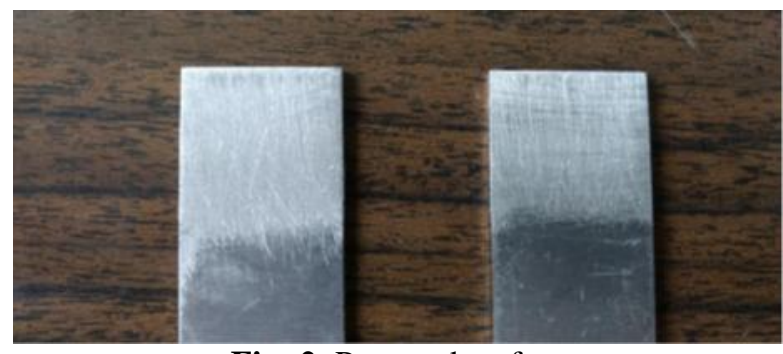

Fig -2: Prepared surface

\subsection{Joint Preparation and Curing}

Aluminium was used as adherend and metal specimen were bonded under single lap joints as per ASTM D1002-99, most widely used adhesive bond test for the single overlap joint. The resin/hardener mix in appropriate ratio was blended to a stage of homogeneous mixture and subsequently applied to the pre-treated and dry joint surfaces as per procedure suggested by the resin manufacturer so that the bond line thickness and reproducibility is maintained. The joint components were assembled and clamped after the application of the binder mix. An even contact pressure throughout the joint area was ensured during curing. Pressure was applied on the bonded assembly through a machine with pressure platens displaying the extent of pressure being applied and has been shown in figure 3 .

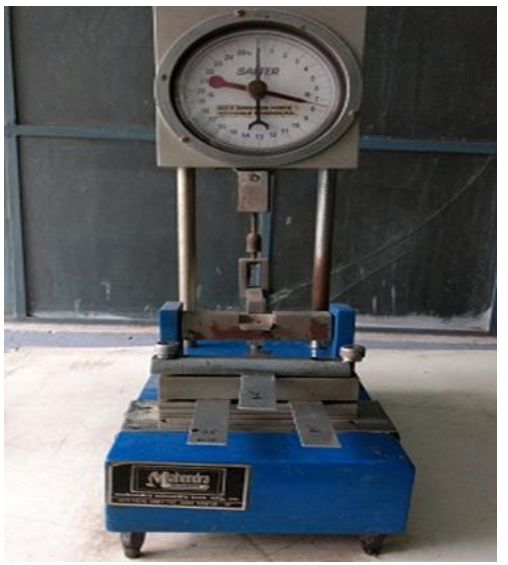

Fig -3: Bond assembly machine 
Guidelines for the bonding conditions have been provided by ASTM D1002-99 which were referred and followed. The same procedure has been used when the mix was loaded with fillers. Fillers were loaded with $2 \%$ by total weight of the binder mix. When looking for specific joint strengths, the optimum overlap length needs to be worked out.

\subsection{Testing}

The prepared specimens were tested on Instron1195 UTM as shown in figure 4. It is screw driven machine with maximum load capacity of $100 \mathrm{kN}$ and minimum load capacity of $5 \mathrm{~N}$ with crosshead speed range from 0.5 to 500 $\mathrm{mm} / \mathrm{min}$. The specimens were mounted on the Instron 1195 UTM ensuring that the axis of the specimen is aligned inline with the axis of the cross-heads in order to simulate a uniform stress condition over the cross-section of the specimen. The tensile tester was programmed to pull the specimen strip at a rate of (testing speed) $1.3 \mathrm{~mm} /$ minute until failure. The testing speed was selected in accordance with ASTM standards D1002-99.

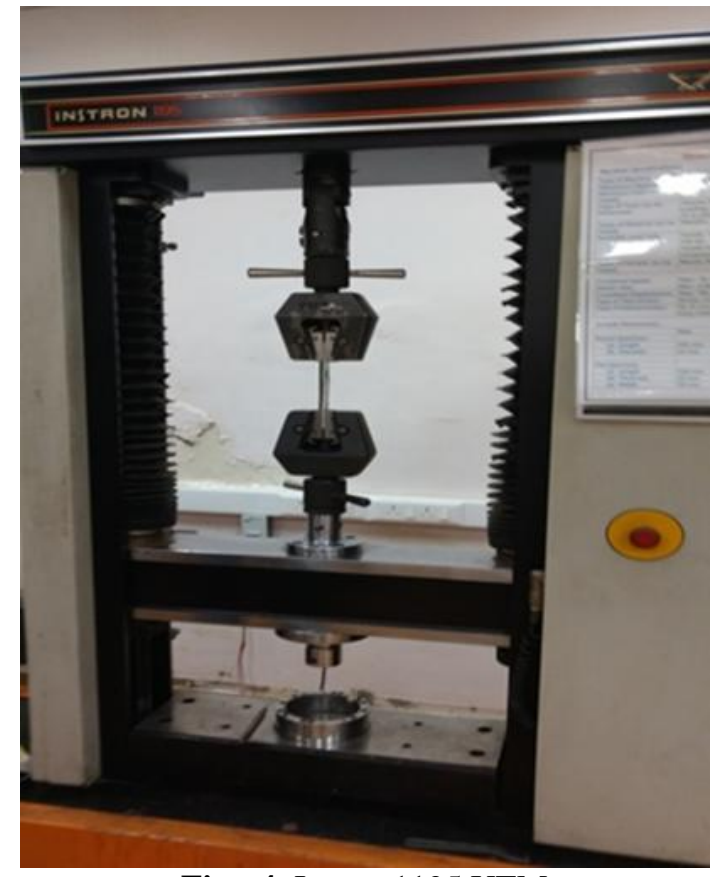

Fig - 4: Instron1195 UTM

\section{RESULTS AND DISCUSSION}

Specimens were prepared of specific joint geometry and cured subsequently as described in earlier section, using aluminium as adherend and two component engineering adhesive for bonding. Prepared specimens named with A$15, \mathrm{~A}-25$ and A-35 are of epoxy resin binder (without filler) with varying overlap length of $15 \mathrm{~mm}, 25 \mathrm{~mm}$, and $35 \mathrm{~mm}$. Specimens named with $\mathrm{H}-15, \mathrm{H}-25$ and $\mathrm{H}-35$ have been prepared with epoxy resin binders loaded with $2 \%$ of alumina powder. Specimen I-15, I-25 and I-35 have been loaded with $2 \%$ of silica filler in epoxy resin binder. These specimens were tested for their load bearing capacity under tensile load on Instron1195 UTM through the standard procedure as described earlier. Table 1 is showing the values of the maximum load attained by the different specimens.
The binder's shear strength, $\tau_{w}$ has been calculated as a maximum shear achieved in a binder layer based on recorded maximum tensile forces for each of the tested joint-specimen as shown by equation (1).

$$
\tau_{w}=\frac{F \max }{m \cdot w}
$$

Joint tensile strength, $\sigma_{h}$ is expressed by equation (2) as a maximum tensile stress transferred crossover through each of the joint-specimen.

$$
\sigma_{h}=\frac{F \max }{h \cdot w}
$$

Table -1: Tested specimens and their maximum load

\begin{tabular}{|l|l|}
\hline Specimens & Maximum load attained $(\mathrm{kN}), F_{\max }$ \\
\hline A-15 & 2.89 \\
\hline A-25 & 4.76 \\
\hline A-35 & 5.24 \\
\hline H-15 & 3.91 \\
\hline H-25 & 5.83 \\
\hline H-35 & 6.04 \\
\hline I-15 & 3.08 \\
\hline I-25 & 5.28 \\
\hline I-35 & 5.89 \\
\hline
\end{tabular}

Adhesive shear strength is worked out from equation (1) and the values of joint tensile strength are calculated by using equation (2), providing the load-bearing capacity of the bonded joint. Chart 1 is showing the load versus displacement pattern for the specific specimen-joint of $\mathrm{H}-35$ under tensile stress. Maximum load obtained has been 6.043 $\mathrm{kN}$.

\section{Load vs Displacement}

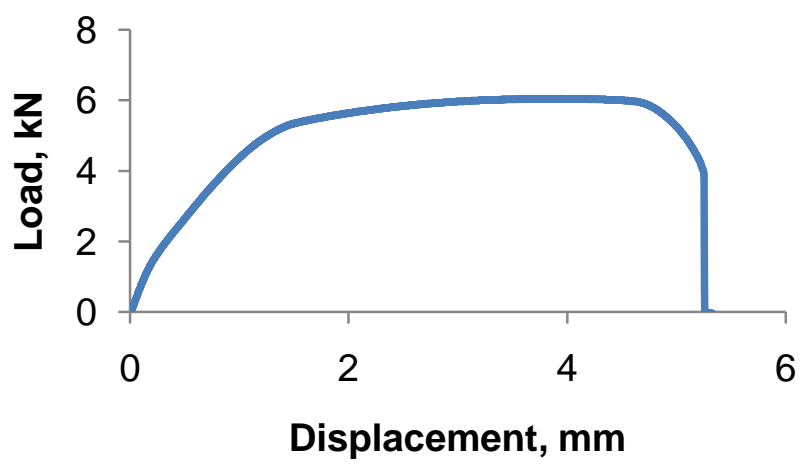

Chart -1: Maximum load obtained

On comparing all specimens, which are, A (epoxy resin without filler), $\mathrm{H}$ (epoxy resin with $2 \%$ alumina powder), and I (epoxy resin with $2 \%$ fumed silica) with different overlap length, specimens-H show the highest strength at all stages of overlap In chart 2, the curves confirm the binder's shear strength distributed through the overlap region. The binder's shear strength has been obtained from equation (1). 
At overlap of $15 \mathrm{~mm}$, the adhesive shear strength was found to be enhanced by around $20 \%$ with the incorporation of 2 $\%$ nano alumina in the epoxy adhesive in comparison to the shear strength of the unfilled epoxy adhesive. The increase in adhesive shear strength was found to be around $7 \%$ with the filling of $2 \%$ fumed silica by weight.
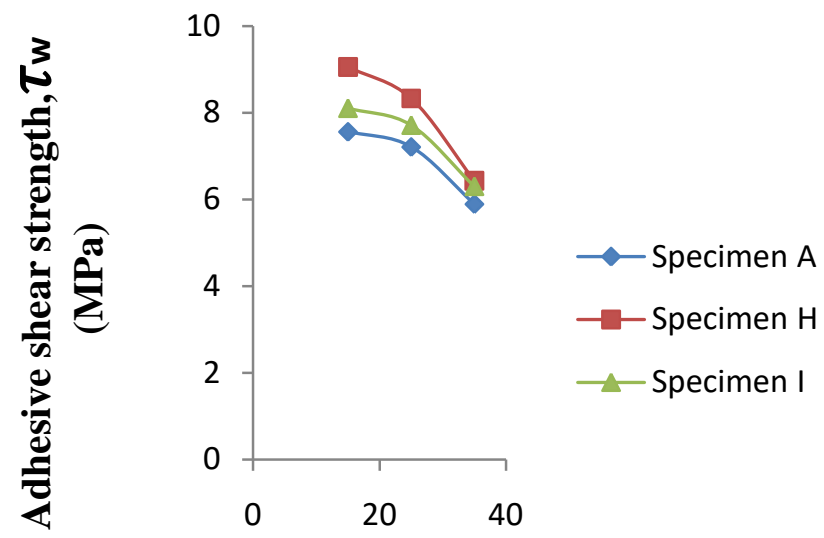

\section{Overlap length, $\mathbf{m m}$}

Chart -2: Binder's shear strength vs overlap length

Joint strength depends on the overlap length as a primary factor, with existing adhesive and adherend properties, design of the joint, bonding as well as conditioning procedure and conditions of loading. It is very necessary to see that the overlap length can be increased only up to the limit of the elastic region of the adherend. Increase of the maximum tensile force is possible only up to the point of reaching yield point of adherend. Beyond this point an excessive deformation of the adherends may lead to failure inside the adherend. This leads to failure of the joint due to crack initiation. The overlap length depends on the type of adhesive as well as adherend type. For joints with elastic adherends and brittle adhesives, limit strength would be obtained and the joint strength is not proportional to the overlap length.

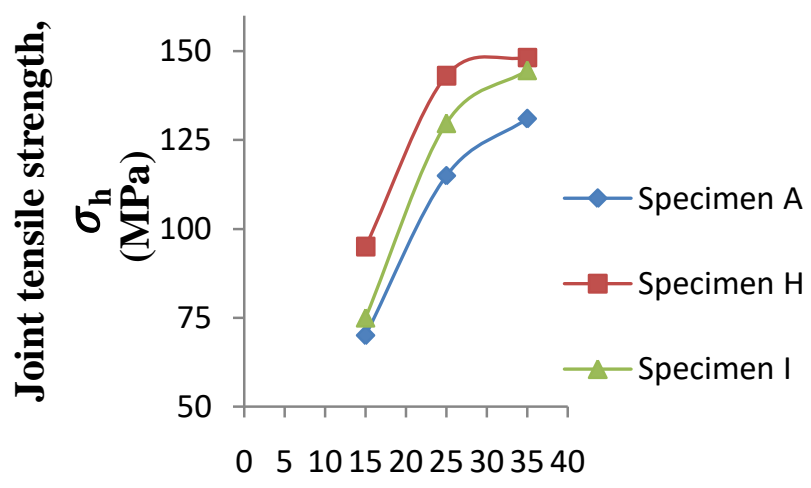

Overlap length, (mm)

Chart -3: Joint tensile strength vs overlap length
The observations of the limit strengths as per chart 3 are in agreement as stated earlier by authors [3, 8]. It is observed in chart 3 that with increasing overlap length, the joint tensile strength increases. The joint tensile strength is depending on overlap length. Overall joint strength (its load bearing capacity, Fmax) increases because of increase in the bonding area. The curves approach to maximum at certain overlap length, which is around $35 \mathrm{~mm}$ for this study. With the $2 \%$ weight ratios of fillers used in the hybrid mixture, the increase in joint tensile strength in comparison to pure epoxy adhesive was increased by around $15 \%$ with nano alumina and by $13 \%$ for the case of fumed silica reinforcement, at overlap of $35 \mathrm{~mm}$.

\section{CONCLUSION}

Using aluminium as the adherend material and two component engineering adhesive as the polymer binder, adherend joint geometry was decided on the basis of ASTM standards. The joint tensile strength and binder shear strength have been determined experimentally. The obtained results would be useful in the composite sectors of the aerospace, automotive, defence and in other industrial areas dealing with composite modules. Joints through adhesives provide advantages over traditional techniques of welding, riveting and bolting methods. Stress concentrations get reduced along with weight and process of manufacturing becomes easy. Additional parameters of corrosion and fatigue resistance and good damping characteristics may be achieved with proper selection of binder and joint design.

Important aspects related to joints in assembly utilizing adhesives depend on surface preparation, complete mixing of all the components of adhesive and filler, pressure application, curing and conditioning procedure. The aim of the work was to investigate the effect of nano-fillers on the bond strength of the polymer adhesives. In comparison to conventional epoxy adhesive, the engineering properties of the aluminium joints prepared using nano-fillers have improved. The results show that the overlap length is directly related to the joint tensile strength, but strongly depends on the mechanical properties of the adherend as well as the type of binder. At certain overlap, limit strength is achieved in joints in the case of elastic adherend and brittle adhesive, leading towards the estimation of optimal overlap. This estimation would be useful in the design of composites for process equipment components as well as structural components. At the optimum overlap length it is possible to reach a maximum load bearing capacity using a minimum quantity of applied adhesive. Type of adherend used in the composite, characteristic of the adhesive as well as type of fillers reinforced would lead towards optimal overlap so that desired shear strength and joint tensile strength is achieved.

\section{ACKNOWLEDGEMENT}

The authors are thankful to Advanced Center for Materials Science, Indian Institute of Technology, Kanpur for facilitating testing of the experimental specimens prepared under research project and hereby acknowledge the same. 


\section{REFERENCES}

[1] Zhai, L., Ling, G., Li, J., Wang, Y., "The effect of nanoparticles on the adhesion of epoxy adhesive". Materials letters. Vol. 60, 2006, 3031-3033.

[2] Ghosh, P.K. and Nukala, S.K., "Properties of adhesive joint of inorganic nano-filler composite adhesive". Indian Journal of Engineering \& Materials Sciences. Vol. 15, 2008, 68-74.

[3] Lucic, M., Stoic, A., Kopac, J., "Investigation of aluminium single lap adhesively bonded joints". Journal of Achievements in Materials \& Mfg. Engg. Vol. 15, 2006, 79-87.

[4] Raos P., Kozak, D., Lucic, M., "Stress-strain analysis of single lap tensile loaded adhesive joints". AIP conference proceeding. 2007.

[5] Lucas, F.M., Carbas, R.J.C., Critchlow, G.W., Figueiredo, M.A.V., "Effect of material, geometry, surface treatment and environment on the shear strength of single lap joints". International Journal of Adhesion \& Adhesives. Vol. 29, 2009, 621-632.

[6] Quddos, A., Samtio, N.H., Syed, A.M., "Characterization and the pattern of surfaces of sealant with nano sized composite materials". Journal of Physics: Conference series 439 (VASSCAA-6), 2013, 1-5

[7] Zhai, L., Ling, G., Wang, Y., "Effect of nano- $\mathrm{Al}_{2} \mathrm{O}_{3}$ on adhesion strength of epoxy adhesive and steel". International Journal of Adhesion \& Adhesives. Vol. 28, 2007, 23-28.

[8] Campilho, R.D.S.G. and Fernandes, T.A.B., "Comparative evaluation of single-lap joints bonded with different adhesives by cohesive zone modelling". Procedia Engineering. Vol. 114, 2015, 102-109.

[9] Zaikin, A.E., Bikmullin, R.S., Gorbunova, I.A., "Characterization of the adhesion interaction of polymers with the surface of filler nanoparticles". Russian Journal of Applied Chemistry. Vol. 80, 2007. 965-970.

[10] ASTM D 1002- 1999. "Standard test method for apparent shear strength of single-lap-joint adhesively bonded metal specimens by tension loading (metalto-metal)". ASTM, PA 19428-2959. 